\title{
The Impact of Social Norms, Trust, and Fairness on Voluntary Tax Compliance in Austria
}

\author{
MARIA KOSTRITSA \\ FH Joanneum, Austria \\ maria.kostritsa@edu.fh-joanneum.at \\ INKEN SITTLER \\ FH Joanneum, Austria \\ inken.sittler@edu.fh-joanneum.at
}

Existing literature stresses the importance of economic factors when aiming to increase voluntary tax compliance. However, emerging voices also point out to relevant social factors, but emphasize that more research needs to be carried out for their verification. Therefore, in this article, research was conducted to provide further evidence to show how social factors have an influence on voluntary tax compliance. The research is the first attempt to replicate the results of the structural model of Jimenez and Iyer (2016) outside of the us, claiming that one's moral standards (personal norms) and perceived fairness directly influence voluntary tax compliance, meanwhile social norms and trust in government have an indirect impact on tax compliance via influencing personal norms and perceived fairness. To achieve a beneficial result, 333 Austrian taxpayers were surveyed in Austria. The data was analysed in spss using frequencies, correlations and regression analysis. The results verify the aforementioned assumptions and emphasize its consideration when aiming to increase voluntary tax compliance.

Key words: voluntary tax compliance, trust, fairness, social factors, Austria https://doi.org/10.26493/1854-4231.12.333-353

\section{Introduction}

According to Statistik Austria (2016), over 6.7 out of 8.6 million inhabitants in Austria are reported as being active taxpayers. The total gross earnings from taxes in 2015 amounted to $€ 182,515.6$ million. Assuming that tax authorities generally aim to maintain and increase tax compliance to ensure a source of earnings, one needs to investigate how tax compliance can be achieved and increased, especially 
when considering that an avoidance of taxes might hamper the legal economy, and cause losses for the state. When examining negative effects of tax avoidance in Austria, one can mention Schneider, Buehn, and Montenegro (2010), who argue that tax burden is the main contributor to the development of shadow economy in Austria. Therefore, the provision of managerial implications through the elaboration of effective and convenient measures for increasing voluntary tax compliance can be assumed to be of a high interest for researchers and tax authorities worldwide.

However, a universal managerial implication may seem difficult to derive when facing possible factors with diverging characteristics (possibly affecting voluntary tax compliance), and when inferring that every country is embedded into a specific context. After testing the slippery slope framework in Austria, Hungary, Romania and Russia, Kogler et al. (2013) concluded that Austrians want to comply with paying taxes. Because by doing so, they would fulfil their responsibility, not only before the government, but also before the society. This draws attention to the relevance of profoundly examining, where aspects need to be taken into account when aiming to achieve voluntary tax compliance. In conclusion, not only the laws and penalties oblige people to pay taxes.

Additionally, when wishing to elaborate effective measures for achieving tax compliance, a careful preparation and selection of specific measures is necessary, as wrongly chosen measures could turn out to be rather self-defeating than achieving expected positive effects. In the case of Austria, Gangl et al. (2014) provides results that underline this apprehension, arguing that a deterrence approach (laws and supervision activities) chosen to achieve tax compliance in Austria does have a negative influence on tax compliance itself. In conclusion, there must be something else, in need of capturing, that influences people's willingness to comply voluntarily.

When considering a possible variety of influencing factors, one should also take in mind that these factors might require different implementations as they can have unequal characteristics. Although a deterrence approach exclusively focuses on control measures implemented from the outside of an individual's sphere (not directly taking into account a person's inner characteristics such as norms and specific beliefs of a person), an approach of targeting social factors does so. At the first glance, it may appear difficult to understand how the inner sphere of an individual is shaped, and how it could be influenced from an external perspective. However, the prospect of a lower need of supervision activities and, hence reduced expenses in 
return of people's will of increasing compliance (based on their inner conviction), clearly shows the importance of considering social factors by tax authorities and researchers. Specific models, which allow one to derive managerial implications that comply with this prospect, should be focused.

Focusing on recently developed models, which can be described to be in accordance with the aforementioned goal of efficiently improving tax compliance, one can emphasize the structural model of Jimenez and Iyer (2016). The authors of this model claim that social factors encourage people to voluntarily pay taxes. Used variables of this model can be divided into dependent and independent variables. As dependent variables, one can state intentions of tax compliance, whereas independent variables can be listed as norms, perceived fairness, and trust, summarized as social factors.

A further breakdown of social factors that are declared as independent variables let one distinguish more easily between social norms and personal norms. Within social norms, the authors of the applied model differentiate between injunctive, descriptive and subjective norms. Injunctive norms refer to the perceptions of which behaviours that most people in a group approve or disapprove of (Aronson, Wilson, and Akert 2010; Cialdini and Trost 1998). In other words, injunctive norms define what one person believes other people's moral standards are. Descriptive norms describe how a person perceives other people's general behaviour (Aronson, Wilson, and Akert 2010). Lastly, subjective norms incorporate peer-pressure. They refer to a one's perceptions about how people close to him/her want him/her to behave (Fishbein and Ajzen 1975). Personal norms are a person's own moral standards and behavioural expectations (Cialdini and Trost 1998; Wenzel 2004a). To distinguish more generally, the three different types of social norms involve an interconnection between the society and the individual, whereas personal norms only look at the individual him/herself. This also helps make visible why social norms appear to be more accessible of an external perspective than personal norms, as they include external factors. This constitutes a possible target for managerial implications.

In a second step of outlining further independent variables, trust in the government can be described as a firm belief in the reliability and ability of the government. Perceived fairness refers to an individual's subjective perceptions that the government acts in a fair way (Bordignon 1993). Furthermore, one has to consider the already stated aim to understand how the inner sphere of an individual, more precisely personal norms, are formed and therefore could be 
influenced. Jimenez and Iyer (2016) stated two assumptions, which allow one to also presume a certain order of the above listed dependent and independent variables. First of all, they claim that social norms influence personal norms that in turn directly influence tax compliance. Secondly, they state that trust in government shapes the individual perception of fairness of the governmental institutions, which then in sequence influences voluntary tax compliance.

Jimenez and Iyer (2016) conclude that social norms influence tax compliance indirectly through personal norms, which successively have a direct impact on tax compliance. Asides from that, they also report an 'interrelated influence' between trust and perceived fairness of the governmental institutions. They claim that trust is an antecedent of perceived fairness, and therefore shapes the fairness perception of an individual.

Considering the above-mentioned assumptions and related recommendations, social factors are important to look at, and may turn out to be an effective and convenient measure to increase tax compliance. On the other hand, however, they still require further evidence and profound elaboration. One can stress the importance of supplementary studies in this research field. Therefore, to provide further evidence for Jimenez and Iyer's assumption that social factors do matter when achieving tax compliance, and comply their recommendation that further research in other countries should be carried out, our research can be classified as the first replication of their model outside of the us.

In summary, the presented research combines a number of relevant social factors under a common model, and analyses their influence on voluntary tax compliance in Austria. The primary data acquired through online and offline surveys in 2017 is used to test the structural model of Jimenez and Iyer (2016), and identify the relationship between various social factors and tax compliance in Austria, hence allowing one to derive beneficial managerial implications.

\section{Theoretical Background}

The topic of tax compliance occupies minds of researchers all over the globe. Tax compliance literature is rather extensive in identifying a broad list of variables influencing tax compliance behaviour. James and Alley (2002) distinguish between economic and behavioural approaches to tax compliance. According to the former approach, taxpayers are viewed to be concerned primarily with financial gains. The latter approach treats taxpayers as honest people willing to comply, if they can trust authorities and perceive their actions as 
fair and equitable. Representatives of the traditional economic approach are Allingham and Sandmo (1972) who propose the utility theory, which explains non-compliance through solely financial gains. Kirchler, Hoelzl, and Wahl (2008) explain tax compliance through power and trust in authorities with the aid of their Slippery Slope Framework. They distinguish between enforced tax compliance, which can be achieved through exercising power, and voluntary tax compliance, which is promoted by building trust-based relationships with taxpayers. Their model clearly shows that there are two approaches when explaining tax compliance behaviour: deterrence (through power) and non-deterrence (through trust and perceived fairness).

Torgler (2002) states that besides economic factors, social norms have a strong effect on tax compliance. In addition, he mentions that traditional deterrence models are not able to explain why people choose to voluntarily comply with tax regulations. Alm, Sanchez, and de Juan (1995) claim that a holistic approach to measure tax compliance needs to be adopted. They argue that when using only the traditional economics-of-crime approach while researching tax compliance behaviour and ignoring an individual's behaviour and motivation, one will not be able to produce consistent results. Paldam (2000) declares that the research field which focuses on the impact of social factors, or social capital on tax compliance, aroused the interest of researchers just recently and still lacks comprehensive and reliable data. Frey and Torgler (2007) stress the importance of social aspects on tax compliance behaviour by stating that the tax behaviour of others defines the individual's behaviour through conditional cooperation. Furthermore, some authors emphasize trust as one of the primary sources of tax compliance behaviour (Kirchler et al. 2008; Slemrod 1998; Gobena and Van Dijke 2016).

When it comes to tax compliance behaviour and its motives, there is a significant difference between voluntary and enforced tax compliance. Enforced tax compliance relies mainly on the system of fines and penalties, which can become very expensive for the government (Alm et al. 2012; Kirchler, Hoelzl, and Wahl 2008), and has little to do with how people's moral standards about tax compliance are formed (Graetz and Wilde 1985)

On the other hand, voluntary tax compliance is cheaper and provides a more efficient way to ensure that taxes are being collected. Silvani and Baer $(1997,11)$ describe voluntary tax compliance as 'timely filing and reporting of required tax information, the correct self-assessment of taxes owed and the timely payment of those taxes 
without enforcement action.' The opinions on what promotes voluntary tax compliance vary among authors. Farrar (2015) and Murphy and Tyler (2008) state that perception of fairness plays an important role in improving voluntary tax compliance in a country. Hartner et al. (2008) additionally mention the effect that national identification has on citizens' compliance behaviour. Van Dijke and Verboon (2010) state that trust functions as a moderating effect in the relationship between perceived fairness and voluntary tax compliance. The authors argue that perceived fairness shows stronger positive effects on compliance behaviour of citizens with low trust in authorities.

\section{Research Questions}

Many authors attribute high importance to the impact of trust on tax compliance (Kirchler, Hoelzl, and Wahl 2008; Slemrod 1998; Gobena and Van Dijke 2016). However, in the model used for the research we can see that, rather than influencing voluntary tax compliance directly, trust affect it indirectly via perceived fairness. Trust is also formed under the impact of personal norms, which in fact, directly affect voluntary tax compliance. Therefore, we concluded that it is crucial to investigate the relationships between trust, perceived fairness, and personal norms. We attempt to prove that there is a relationship between trust and fairness. In order to understand how trust and fairness relate to in other, the first research question is introduced, and formulated as follows:

RESEARCH QUESTION 1 How strongly is fairness perception related to trust in government in Austria?

но There is no relation between fairness perception and trust in government in Austria.

$\mathrm{H} 1$ There is a relation between fairness perception and trust in government in Austria.

One of the main points of the current research is to provide evidence that individual taxpayer's personal norms to a certain extent influence the formation of trust towards authorities. Therefore, the second question looks into the relationships between trust and personal norms.

RESEARCH QUESTION 2 How strongly are personal norms of tax compliance related to trust in government in Austria?

но There is no relation between personal norms and trust in government in Austria.

$\mathrm{H} 2$ There is a relation between personal norms and trust in government in Austria. 
After determining the relationships between personal norms and trust, and perceived fairness and trust, we analyse how various social factors influence voluntary tax compliance in Austria. Under the research question, a number of hypotheses are formulated. The hypotheses assume a relationship between such social factors, as injunctive, descriptive, subjective, and personal norms, as well as perception of fairness, and tax compliance behaviour of taxpayers in Austria.

RESEARCH QUESTION 3 What is the contribution of social factors in explaining the variation in tax compliance in Austria?

но There is no relationship between social factors and tax compliance in Austria.

н3 There is a relationship between social factors and tax compliance in Austria.

н3А There is a relationship between injunctive norms and personal norms.

нзв There is a relationship between descriptive norms and personal norms.

нзс There is a relationship between subjective norms and personal norms.

H3D There is a relationship between personal norms and tax compliance.

н3Е There is a relationship between fairness perceptions and tax compliance.

\section{Methodology}

\section{PROCEDURE}

For collecting the required data, a survey was used. The original questions that were combined under the questionnaire are available in English. Because the data collection takes place in Austria and among Austrian population, the questionnaire had to be professionally translated into German.

The questionnaire was pretested on a group of 20 people. The pretest allowed to spot mistakes in the questionnaire, such as typos, confusing wordings of some of the questions.

The survey was distributed both online and offline to mitigate the risks of non-response, respondent errors, and increase the coverage, namely the chances to reach the minimum defined sample size of 312 respondents. Bonnel, Bayart, and Smith (2015) claim that various modes can be used simultaneously to improve coverage, and de- 
crease the coverage biases. Moreover, the mix of online and offline survey modes allow to significantly boost response rate and reach a wider population, which otherwise would not be cost efficient (Nulty 2008).

Therefore, the data was collected via online and offline questionnaire. The online questionnaire was designed with and administered through QuestionPro. The link to the questionnaire was distributed via social media channels, like Facebook groups and event pages and WhatsApp, as well as via direct e-mailing, and snowball sampling.

The offline questionnaire was distributed among students in various degree programs at $\mathrm{FH}$ Joanneum, as well as among the teaching and non-teaching staff at FH Joanneum campuses in Graz and Kapfenberg. Moreover, street polls in Graz and Knittelfeld were used to collect responses, as well as BFI office in Graz. In order to ensure that anonymity of respondents is ensured and the sensitivity of the topic is taken into account, offline questionnaires were distributed in enveloped that could be sealed and dropped into a box without field researches being able to identify identities of respondent and their answers. For improving response rates an incentive system for participants was introduced in a form of 0.15 EUR donation per participant to an Austrian charity organization 'Herz bewegt' working to provide free of charge heart surgeries for children in Austria.

Both online and offline surveys were opened on May 5th 2017 and closed on May 26th 2017 when the sample size was overreached. The final response rate for the period of three weeks is 333 respondents.

MEASURES

The questionnaire consists of two qualifying questions in the introductory part. The main part of the questionnaire consists of 26 questions divided into eight sections (see Appendix). Each one of the first seven sections relate to the variables under research. The last section collects demographic data of respondents, such as age, education level, and gender. Table 1 presents the sources of the questions used in the survey.

The basic data is collected on a 7-point Likert scale, where 1 signifies strong disagreement with a statement, and 7 strong agreement. In the case of the seventh section, where hypothetical tax compliance is measured, 1 on the 7-point Likert scale denotes that a decision in a certain situation is very unlikely, and 7 very likely.

\section{SAMPLE}

In order to make sure that statistically significant results can be achieved, and a small interaction effect detected, the appropriate 
TABLE 1 Measures and Sources

\begin{tabular}{ll}
\hline Variable & Source \\
\hline Injunctive norms & Bobek, Roberts, and Sweeney (2007) \\
Descriptive norms & Bobek, Roberts, and Sweeney (2007) \\
Subjective norms & Blanthorne and Kaplan (2008) \\
Personal norms & Bobek, Roberts, and Sweeney (2007) \\
Trust & Kogler et al. (2013) \\
Perceived fairness & Nakayachi and Cvetkovich (2010); Herda and Lavelle (2011) \\
Voluntary tax compl. & Blanthorne and Kaplan (2008); Kogler et al. (2013) \\
\hline
\end{tabular}

sample size was determined. According to Cohen $(1988,75)$ that those researching behavioural differences 'in personality, attitude, and ability, frequently take recourse to correlational analysis as an investigative tool in both pure and applied studies.' He continues by stating that in order to be able to investigate such individual differences between variables using statistical analysis the Pearson product-moment correlation coefficient, $r^{\prime}$ shall be applied (p. 75). What is important to note is that it is acceptable to assume a normal distribution of the data, since a significantly large sample is used in the analysis.

According to the guidelines from Cohen (1988), a small effect size of 0.2 for the survey was adopted, because the research is rather new and it is hard to estimate the influence of all extraneous variables. Since the direction of the relationship between variable are clearly specified in the Structural Model of Jimenez and Iyer (2016), one is able to use one-tailed test with a significance of $95 \%$, or 0.5 significance criterion (with only a $5 \%$ probability of making a Type I mistake by accepting that there is an effect, when in reality it is not), and power of 0.8 , in other words the probability of $80 \%$ of detecting an effect that is actually found in the population. Based on the above-mentioned criteria, the sample size is estimated at a number of 312 respondents.

\section{Results}

The first step of the data analysis was to check the collected data on its reliability using the Cronbach's alpha analysis. The Cronbach's alpha for the data set reached a value of 0.852 , which means that the data set can be classified as highly reliable. The total number of items checked was 23 and includes the variables for each of our main categories which are called Injunctive Norms (INJ), Subjective Norms (subJ), Descriptive Norms (DESC), Personal Norms (Pers), Trust (TRU), Perceived Fairness (FAIR), and Voluntary Tax Compliance (сомP).

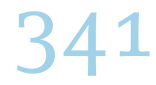


TABLE 2 Sample Description

\begin{tabular}{llrr}
\hline Characteristics & & Frequency & Percentage \\
\hline Age & $18-24$ & 93 & 27.9 \\
& $25-34$ & 138 & 41.4 \\
& $35-44$ & 44 & 13.2 \\
& $45-54$ & 29 & 8.7 \\
& $55-64$ & 19 & 5.7 \\
& $65-74$ & 7 & 2.1 \\
& Missing & 3 & 0.9 \\
\hline Gender & Male & 152 & 45.6 \\
& Female & 173 & 52.0 \\
& Other & 5 & 1.5 \\
& Missing & 3 & 0.9 \\
\hline Education level & Middle school & 9 & 2.7 \\
& High school & 123 & 36.9 \\
& Professional training & 40 & 12.0 \\
& Bachelor degree & 79 & 23.7 \\
& Master degree & 59 & 17.7 \\
& Doctorate degree & 20 & 6.0 \\
& Missing & 3 & 0.9 \\
\hline Total & & 333 & 100 \\
\hline
\end{tabular}

The main age-group of our survey-participants was ' $25-34$ ' which includes 138 out of 333 participants and accounts for $41.4 \%$ of the total answers. The second frequently used answer for the category 'age groups' was '18-24' with 93 participants out of 333 stating that they belong to this age category. This category accounts for $27.9 \%$ of the total answers. The minor age group of our participants was '65$74^{\prime}$ which included seven out of 333 participants and accounts for $2.1 \%$.

The targeted gender-mix was reached in our survey and the balance in terms of gender-based answers is given. The female group amounted for 173 out of 333 participants or $52 \%$ of the total answers. 152 male participants account for $45.6 \%$ of the total answers. Five out of 333 participants picked 'other' as their gender, which is $1.5 \%$.

The major number of participants picked 'high school diploma or equivalent' as their education level, which includes 123 out of 333 participants and accounts for $36.9 \%$ of the total answers. The second frequently used answer for the category was 'bachelor degree' with 79 participants out of 333 (45.6\%). The minor education level group of our participants was 'middle school or equivalent' which included nine out of 333 participants and accounts for $2.7 \%$. Also, it is noticeable that although when depicting a high number of respondents stating to have a high school diploma or equivalent, a good mixture 
TABLE 3 Correlations between Measures

\begin{tabular}{rrrrrrrr}
\hline & $(1)$ & $(2)$ & $(3)$ & $(4)$ & $(5)$ & $(6)$ & $(7)$ \\
\hline$(1)$ & 1 & $0.438^{*}$ & $0.329^{*}$ & $0.264^{*}$ & & & \\
$(2)$ & $0.438^{*}$ & 1 & $0.344^{*}$ & $0.191^{*}$ & & & \\
$(3)$ & $0.329^{*}$ & $0.344^{*}$ & 1 & $0.270^{*}$ & & & \\
$(4)$ & $0.264^{*}$ & $0.191^{*}$ & $0.270^{*}$ & 1 & & $0.215^{*}$ & $0.343^{*}$ \\
$(5)$ & & & & & 1 & $0.701^{*}$ & $0.190^{*}$ \\
$(6)$ & & & & $0.215^{*}$ & $0.701^{*}$ & 1 & \\
$(7)$ & & & & $0.343^{*}$ & $0.190^{*}$ & & 1 \\
\hline
\end{tabular}

Notes Column headings are as follows: (1) injunctive norms, (2) descriptive norms, (3) subjective norms, (4) personal norms, (5) perceived fairness, (6) trust, (7) voluntary tax compliance. ${ }^{*}$ Correlation is significant at the 0.01 level (1-tailed).

of answers of all age categories is given and showing a mixed opinion of people of all education levels.

The number of missing values in all demographic questions is 3 out of 333 responses, which accounts for $0.9 \%$ of the total answers.

With the support of a product-moment correlation, we wanted to check if there are relationships among variables. As seen from table 3, all correlations are significant at the level 0.01 (1-tailed). The correlation coefficient between trust and perceived fairness reaches a value of 0.701 , meaning that there is a strong correlation between the two variables. There is also a moderate correlation between voluntary tax compliance and personal norms with a correlation coefficient of 0.343 .

The correlation between trust and personal norms is weak at 0.215. Similar weak correlations are identified between personal norms and injunctive norms (0.264), personal norms and descriptive norms (0.191), personal norms and subjective norms (0.270), and voluntary tax compliance and perceived fairness (0.190).

The bivariate regression analysis of personal norms and trust shows that the significance of this regression reached a value of 0.000 , which means that the alternative hypothesis (H2) needs to be accepted. Furthermore, the beta-weight of this regression reached a value of 0.227 , which states that the variable 'Personal Norms' has a weak positive influence on the variable 'Trust.' The Durbin-Watson test reached a value of 1.737. This means that the regression does not lack any form of an autocorrelation error of the residues.

The regression between the variables 'Personal Norms' and 'Voluntary Tax Compliance' with the significance of 0.000 and the betaweight of 0.343 shows that the variable 'Personal Norms' has a moderate positive influence on the variable 'Voluntary Tax Compliance.'

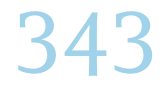


The Durbin-Watson test reached a value of 1.927. The regression between 'Trust' and 'Perceived Fairness' is significant at o.ooo. Furthermore, the beta-weight of this regression reached a value of 0.703 , which states that the variable 'Trust' has a strong positive influence on the variable 'Perceived Fairness.' The Durbin-Watson test shows a value of 1.959. The regression analysis of 'Perceived Fairness' and 'Voluntary Tax Compliance' is significant at 0.000 with the beta-weight of this regression reached a value of 0.209 , which states that the variable 'Perceived Fairness' has a weak positive influence on the variable 'Voluntary Tax Compliance.' The Durbin-Watson test reached a value of 1.898 .

The multiple regression analysis between variables 'Injunctive-,' 'Descriptive-,' 'Subjective-Norms' and the variable 'Personal Norms' starts with the results of the Durbin-Watson test. The value of 1.983 represents a perfect model fit.

The significance of the regression between the variables 'Injunctive Norms' and 'Personal Norms' reached a value of 0.002 , which means that the alternative hypothesis ( $\mathrm{H} 1$ ) for this regression needs to be accepted. The beta-weight of this regression reached a value of 0.183 , which states that the variable 'Injunctive-Norms' has a weak positive influence on the variable 'Personal-Norms.'

Also, the significance of the regression between the variables 'Subjective Norms' and 'Personal Norms' (significance value of 0.002), reached a score below 0.05 , which leads to the fact that the alternative hypothesis ( $\mathrm{H} 1$ ) for this regression needs to be accepted. The beta-weight of this regression reached a value of 0.199, which states that the variable 'Subjective-Norms' has a weak positive influence on the variable 'Personal-Norms.'

On the other hand, the significance of the regression between the variables 'Descriptive Norms' and 'Personal Norms' reached a value of 0.459 , which means that the null hypothesis (но) for this regression needs to be accepted. It means that descriptive norms have no influence on personal norms.

\section{Discussion}

The presented research was carried out to provide further evidence that social factors do matter when aiming to achieve voluntary tax compliance. The research field of voluntary tax compliance represents a rather complex thematic area as it may be affected by many different factors. However, when revising existing literature, one can recognize that approaches still mainly rely on deterrence factors and/or do not capture the impact of social factors sufficiently. Based 
on this research gap, we replicated the structural model of Jimenez and Iyer (2016) that shows how social factors influence tax compliance. In contrast to the original study carried out in the us, we conducted our research in Austria, focusing on current and previous Austrian taxpayers.

Our findings support the results of Jimenez and Iyer, observing only some slight differences. The used model claims a relationship among the different variables and lets one arrange a specific model order. When revising our results based on the product-moment correlation, one can stress the strong relationship between the two variables of 'Trust' and 'Perceived fairness.' A moderate relationship can be observed between 'Personal Norms' and 'Voluntary Tax Compliance.' All other relationships are classified as being 'weak.' A further regression analysis let us accept all alternative hypotheses with an exception of н3в, where a null hypothesis is to be accepted. The results clearly show that social factors should be considered in the research field of voluntary tax compliance.

To our knowledge, our research constitutes the first attempt to replicate the study of Jimenez and Iyer outside the us. Therefore, a direct comparison of results to other attempts carried out are limited and relies on the results of the original study. The findings of both papers suggest that social norms have a significant influence on tax decisions. One can highlight the different sample size, as Jimenez and Iyer (2016) conducted the survey with 217 us taxpayers whereas our results include the responses of 333 people in Austria, who pay taxes or have previously paid taxes in the country. Coherent with the findings of Jimenez and Iyer, we identified a low correlation between injunctive and personal norms, and subjective and personal norms. Descriptive norms and personal norms depict a weaker correlation than in the research of Jimenez and Iyer. One difference can be seen in the correlation between personal norms and compliance intentions. Jimenez and Iyer researched a value of 0.56, which represents a medium correlation, whereas our findings in Austria show a low correlation (0.343). There is a similarity in the correlation of trust in government and perceived fairness as they represent the highest correlation between two variables in both surveys. The correlation between trust and compliance intentions is the lowest.

There is evidence in literature showing that not only deterrence, but also social factors can positively influence tax compliance. To provide a broader comparison, other studies including social factors can be used. Unfortunately, we are not able to provide evidence that gender or education influence tax compliance. Other studies, how- 
ever, consider the impact of gender on tax compliance behaviours. Kogler et al. (2013), for example, state that females are more tax compliant and show higher tax morale than males.

Considering the different social factors that may influence voluntary tax compliance, one can state a varying focus on different factors in literature. Kirchler, Hoelzl, and Wahl (2008) state that trust is, besides power, one major dimension of their Slippery Slope Framework and see the perceived fairness of the tax system as an antecedent of trust. Our research shows that the perceived fairness stimulates voluntary tax compliance in Austria, particularly among taxpayers with low trust in authorities (Van Dijke and Verboon 2010). Thus, according to the used model of Jimenez and Iyer, trust is an antecedent of perceived fairness, which contradicts to the aforementioned order stated by Kichler, Hoelzl, and Wahl (2008).

The findings of Mas'ud, Manaf, and Saad (2014) provide further evidence for social factors using the Slippery Slope Framework. According to the authors, trust is an important variable when examining voluntary tax compliance and they pinpoint a direct link between trust and power. Therefore, the interconnection between the power of and trust in tax authorities can be emphasized, which significantly changes the behaviour of people to be tax compliant. In our study, trust in government strongly influences the perceived fairness of the people who pay taxes. In turn, perceived fairness is directly related to the tax compliance intentions. Therefore, the model of Jimenez and Iyer may not include the power of tax authorities, but rather focuses on perceived fairness, which can be seen as an important variable as well. This comparison clearly shows the difficulty in examining which variables should be tested while confronting the dilemma of keeping the model applicable, efficient, and understandable.

Wenzel (2004b) conducted a survey about tax compliance in Australia focusing on social and personal norms. The results showed that the behaviours of people, who strongly identify with a group, are more influenced by social norms than those of people who do not identify with a group. Controlling the personal norms reduced the effect of social norms on the people who identified with the group. In addition, his research showed that the effectiveness of approaches to achieve tax compliance depends on perceived social norms, which are later on incorporated as personal norms. Thus, perceived tax honesty in the society reduces the requirement of a deterrence measurement. In our research project, we did not divide our participants into two different groups, but the results are comparable to the effect of trust and perceived fairness investigated in the used model. There 
is a strong correlation between trust in government and perceived fairness. If the people feel they are being treated fairly, they are more likely to not evade taxes. In turn, trust has a relation to personal norms. Hence, the more trusted the government is, the higher the moral standard of the population. Moreover, the model of Jimenez and Iyer, similar to the approach of Wenzel, states a specific order of social factors, claiming that social norms are antecedents of personal norms. Considering that social norms include external factors and are therefore easier to influence than personal norms, their consideration can be evaluated as crucial even if they only affect voluntary tax compliance indirectly.

\section{Conclusions}

The current paper is the first study of tax morale based on the structural model of Jimenez and Iyer (2016), after the original model had been introduced and tested among taxpayers in the us. The research adopts the proposed model and tests it in a new environment, focusing on taxpayers in Austria. This empirical study allows the identification of interrelated non-deterrence variables effects on voluntary tax compliance in Austria, in comparison to a large body of existing studies that only partially look at social factors, giving preference to mostly economic factors. Thus, this study rose from the research gap that social factors in conjunction with voluntary tax compliance are not sufficiently captured in current research and agrees with former literature that further studies are required.

We used a deductive verification to successfully replicate Jimenez and Iyer's model in Austria. The theoretical model contains seven variables, which are injunctive norms, descriptive norms, subjective norms, personal norms; trust in government, perceived fairness, and compliance intentions. Based on the number of used variables, the model can be classified as being rather complex, but also as approaching the reality more precisely as the model does not reduce the complex research field to a few variables. However, one needs to mention that the model disregards economic factors entirely.

This research was carried out to investigate and to prove the relationship between social factors and voluntary tax compliance. Despite challenges with measuring voluntary tax compliance in Austria, the research offers valuable insight into the relationship between social factors and tax compliance, emphasizing the importance of addressing voluntary tax compliance separately from enforced tax compliance. The results clearly show that the listed social factors do influence voluntary tax compliance in Austria, but can 
be distinguished further, according to how they exert their impact. While the variable of trust and social norms such as injunctive, descriptive, and subjective norms have an indirect impact on voluntary tax compliance, personal norms and perceived fairness can be assumed as direct influencing factors of voluntary tax compliance. Our results only differ slightly from the results of Jimenez and Iyer and we can therefore approve their model.

Moreover, we were able to reach 333 responses and therefore passed our estimated sample size of 312. The participation of genders was almost equal, the common age groups were between 25 and 34 years, and the average education level of participants was a high school diploma. The overall Crombach's Alpha of 0.852 shows that the results are reliable. The strongest correlations can be seen between trust in government and perceived fairness. Finally, we could accept all alternative hypotheses with an exception of нзв.

When pointing out possible beneficial managerial implications that could be derived from the outcomes of this study, one can stress the importance of considering social factors when aiming to increase voluntary tax compliance. We also recommend being aware of the complexity of aspects that can influence tax compliance behaviour and to consider policies carefully with respect to the status quo in Austria, due to the consequences which instruments and strategies could have. However, we recognize that strategies involving social factors would need to be developed according to a longterm approach and are more difficult to observe and to transform into numbers. Nevertheless, taking into mind possible beneficial outcomes, the importance of considering social factors cannot be stressed enough.

Furthermore, the structural model of Jimenez and Iyer provides an orientation regarding where to act when aiming to increase voluntary tax compliance. The used model differentiates between direct and indirect influencing variables of voluntary tax compliance and therefore offers a specific order of the variables. Whereas direct influencing variables do not include external factors, indirect influencing variables do and can therefore be assumed to be more easily shaped. Moreover, the model is based on personal perceptions of individuals and offers insight into how these perceptions are formed and let one assume where corrections could be carried out.

\section{Limitations and Research Outlook}

The present study made clear that looking at only social factors nor just deterrence factors is an appropriate approach to finding all of 
the answers. Speaking about a sensitive topic such as tax compliance, we can say that social factors have a big influence on voluntary tax compliance in Austria, but we cannot say that a strong ethical view about paying taxes makes deterrence factors ineffective. The used model of Jimenez and Iyer is limited to only social factors, and does not consider economic factors, which could matter.

As economic and social factors can both explain tax compliance, one could suggest modifying the model of Jimenez and Iyer through including an economic dimension. However, this claim would result in the need of an amplified questionnaire, which therefore could lead to a higher risk of impeding the data collection through overexerting respondents and through requiring more time, effort and costs. Therefore, one needs to balance the trade-off between striving for accuracy of the current model and the risk of overburdening respondents because of the need for more information.

Moreover, as the model of Jimenez and Iyer was developed quite recently, it appears to be difficult to find comparable literature for our results. To our knowledge, we are the first ones replicating their study in another country. Similar to the research of Jimenez and Iyer, our results cannot be generalized beyond all countries. Considering that social factors might vary geographically, our results need to be seen in the regional context of Austria. One should keep in mind specific conditions and the context of a country, e.g. the state system, history, tax system, which might have an influence on social factors and therefore why results cannot be generalized across borders.

A further limitation is the difficulty to grasp real compliance behaviour as the model focuses on compliance intentions. When evaluating the results, one should be mindful of the validity of the hypothetical scenarios, as they do not compulsorily depict reality. This limitation needs to be stressed in context of the used sample of this study as well. Taxpayers may need to be differentiated more specifically according to different criteria, e.g. whether they are employed or self-employed. This aspect was not included in our survey.

In conclusion, this study focused on bringing evidence that social factors do have an impact on compliance intentions. In order to better understand the impacts on compliance intentions, further research could be completed on distinguishing differences in social norms and tax behaviour regarding different groups, e.g. employed and self-employed people, men and women, or according to a certain income, age or education level. A group comparison was not conducted in this research, but could be an incentive for further research. 


\section{Appendix: Scales Used in the Questionnaire}

\section{INJUNCTIVE NORMS SUBSCALE}

1. Das Umgehen von Steuerzahlungen ist gesellschaftlich akzeptiert, egal durch welche Mittel.

2. Meiner Meinung nach sind Steuerhinterziehungen ethisch vertretbar, wenn ich mit ihnen ungestraft davonkomme.

3. Die meisten Leute würden alles tun, um Steuerzahlungen zu umgehen.

\section{DESCRIPTIVE NORMS SUBSCALE}

4. Steuerhinterziehung ist weit verbreitet in Österreich.

5. Ich glaube, die meisten Leute denken, dass es in Ordnung ist, Vorsteuerabzüge in kleinem Umfang zu "polstern« um zu versteuerndes Einkommen zu reduzieren.

\section{SUBJECTIVE NORMS SUBSCALE}

6. Meine Familie bestärkt mich, Einkommen bei meiner Einkommenssteuererklärung zu niedrig anzusetzen.

7. Meine Freunde bestärken mich, Einkommen bei meiner Einkommenssteuererklärung zu niedrig anzusetzen.

8. Meine Arbeitskollegen/Studienkollegen bestärken mich, Einkommen bei meiner Einkommenssteuererklärung zu niedrig anzusetzen.

\section{PERSONAL NORMS SUBSCALE}

9. Ich denke, es wäre moralisch falsch, zusätzliche 1000 Euro, welche nicht separat als Verdienst angegeben werden, anzunehmen.

10. Wenn ich dabei erwischt werden würde, wie ich Steuern hinterziehe, würde ich mich schämen.

11. Wenn ich damit »durchkommen würde«, keine Steuern zu zahlen, dann würde ich mich schuldig fühlen.

\section{TRUST SUBSCALE}

12. Ich kann der österreichischen Regierung allgemein vertrauen, dass sie immer das tut, was richtig ist.

13. In Österreich werden die Interessen einiger eher berücksichtigt, als die Interessen der Gesellschaft.

14. Die in der Regierung sitzenden Personen verschwenden viel Geld, welches wir als Steuern gezahlt haben.

15. Die meisten Leute der gewählten Regierung sind klug und wissen, was sie tun.

16. Wenige Leute in der gewählten Regierung sind ehrlich. 
PERCIEVED FAIRNESS SUBSCALE

17. Die Regierung schlägt gerechte Politikmaßnahmen vor.

18. Die Regierung setzt Politikmaßnahmen gerecht durch.

19. Im Großen und Ganzen werde ich fair von der Regierung behandelt.

20. Im Großen und Ganzen kann ich darauf zählen, dass die Regierung gerecht ist.

\section{HYPOTHETICAL SCENARIOS: VOLUNTARY TAX COMPLIANCE SUBSCALE}

21. Stellen Sie sich vor, dass Sie auf einer Geschäftsreise in eine Stadt gegangen sind, in der auch gute Freunde von Ihnen wohnhaft sind. Nachdem das Geschäftliche erledigt ist, entscheiden Sie sich, Ihre Freunde zum Abendessen in ein Restaurant einzuladen. Wie wahrscheinlich werden Sie diese Restaurantrechnungen als Geschäftsessen angeben.

22. Stellen Sie sich vor, Sie erhalten zusätzliche 2,00o Euro Geschäftsumsatz in bar, welches nicht separat den Steuerbehörden gemeldet wurde. Wie wahrscheinlich würden Sie diese Einkünfte bei der Steuererklärung angeben?

23. Stellen Sie sich vor, Sie erhalten 1,500 Euro Mieterträge in bar, welche nicht separat den Steuerbehörden gemeldet wurden. Wie wahrscheinlich würden Sie diese Einkünfte bei der Steuererklärung angeben?

\section{References}

Allingham, M. G., and A. Sandmo. 1972. 'Income Tax Evasion: A Theoretical Analysis.' Journal of Public Economics 1:323-38.

Alm, J., E. Kirchler, S. Muehlbacher, K. Gangl, E. Hofmann, C. Kogler, and M. Pollai. 2012. 'Rethinking the Research Paradigms for Analysing Tax Compliance Behaviour.' cesifo Forum 13(2): 33-40.

Alm, J., I. Sanchez, and A. de Juan. 1995. 'Economic and Noneconomic Factors in Tax Compliance.' Kyklos 48 (1): 1-18.

Aronson, E., T. D. Wilson, and R. M. Akert. 2010. Social Psychology. Upper Saddle River, NJ: Pearson Prentice Hall.

Blanthorne, C., and S. Kaplan. 2008. 'An Egocentric Model of the Relations among the Opportunity to Underreport, Social Norms, Ethical Beliefs, and Underreporting Behaviour.' Accounting, Organizations and Society 33:684-703.

Bobek, D. D., R. W. Roberts, and J. T. Sweeney. 2007. 'The Social Norms of Tax Compliance: Evidence from Australia, Singapore, and the United States.' Journal of Business Ethics 74:49-64.

Bonnel, P., C. Bayart, and B. Smith. 2015. 'Workshop Synthesis: Comparing and Combining Survey Modes.' Transportation Research Procedia 11:108-17.

Bordignon, M. 1993. 'A Fairness Approach to Income Tax Evasion.' Journal of Public Economics 52 (3): 345-62. 
Cialdini, R., and M. Trost. 1998. 'Social Influence: Social Norms, Conformity, and Compliance.' In The Handbook of Social Psychology, edited by D. Gilbert, S. Fiske, and G. Lindzey, 151-92. 4th ed. New York, NY: Oxford University Press.

Cohen, J. 1988. Statistical Power Analysis for the Behavioural Sciences. New York: Routledge.

Farrar, J. 2015. 'An Empirical Analysis of Taxpayers' Fairness Preferences from Canada's Taxpayer Bill of Rights.' Journal of Accounting and Taxation 7 (5): 71-9.

Feld, L. P., and B. S. Frey. 2007. 'Tax Compliance as the Result of a Psychological Tax Contract.' Law and Policy 29:102-20.

Fishbein, M., and I. Ajzen. 1975. Belief, Attitude, Intention and Behaviour: An Introduction to Theory and Research. Reading, mA: AddisonWesley.

Frey, B. S., and B. Torgler. 2007. 'Tax Morale and Conditional Cooperation.' Journal of Comparative Economics 35:136-59.

Gangl, K., B. Torgler, E. Kirchler, E., Hofmann, E. 2014. 'Effects of Supervision on Tax Compliance: Evidence from a Field Experiment in Austria.' Economic Letters 123:378-82.

Gobena, L. B., and M. Van Dijke. 2016. 'Power, Justice, and Trust: A Moderated Mediation Analysis of Tax Compliance among Ethiopian Business Owners.' Journal of Economic Psychology 52:24-37.

Graetz, M. J., and L. L. Wilde. 1985. 'The Economics of Tax Compliance: Facts and Fantasy.' National Tax Journal 38:355-63.

Hartner, M., S. Rechberger, E. Kirchler, and A. Schabmann. 2008. 'Procedural Fairness and Tax Compliance.' Economic Analysis and Policy 38 (1): 137-52.

Herda, D. N., and J. J. Lavelle. 2011. 'The Effects of Organizational Fairness and Commitment on the Extent of Benefits Big Four Alumni Provide Their Former Firm.' Accounting, Organizations and Society 36:156-66.

James, S., and C. Alley. 2002. 'Tax Compliance, Self-Assessment System and Tax Administration.' Journal of Finance and Management in Public Services 2 (2): 27-42.

Jimenez, P., and G. S. Iyer. 2016. 'Tax Compliance in a Social Setting: The Influence of Social Norms, Trust in Government, and Perceived Fairness on Taxpayer Compliance.' Advances in Accounting 34:17-26.

Kirchler, E., E. Hoelzl, and I. Wahl. 2008. 'Enforced Versus Voluntary Tax Compliance: The “Slippery Slope" Framework.' Journal of Economic Psychology 29 (2): 210-25.

Kogler, C., L. Batrancea, A. Nichita, J. Pantya, A. Belianin, and E. Kirchler. 2013. 'Trust and Power as Determinants of Tax Compliance: Testing the Assumptions of the Slippery Slope Framework in Austria, Hungary, Romania and Russia.' Journal of Economic Psychology 34:169-80. 
Mas'ud, A., N. A. A. Manaf, and N. Saad. 2014. 'Do Trust and Power Moderate Each Other in Relation to tax Compliance.' Procedia: Social and Behavioral Sciences 164:49-54.

Murphy, K., and T. Tyler. 2008. 'Procedural Justice and Compliance Behaviour: The Mediating Role of Emotions.' European Journal of Social Psychology 38 (4): 652-68.

Nakayachi, K., and G. Cvetkovich. 2010. 'Public Trust in Government Concerning Tobacco Control in Japan.' Risk Analysis 30 (1): 143-52.

Nulty, D. D. 2008. 'The Adequacy of Response Rates to Online and Paper Surveys: What Can Be Done?' Assessment and Evaluation in Higher Education 33 (3): 301-14.

Onu, D., and L. Oats. 2015. 'The Role of Social Norms in Tax Compliance: Theoretical Overview and Practical Implications.' Journal of Tax Administration 1 (1): 113-37.

Paldam, M. 2000. 'Social Capital: One or Many? Definition and Measurement.' Journal of Economic Surveys 14:629-53.

Schneider, F., A. Buehn, and C. E. Montenegro. 2010. 'Shadow Economies all over the World: New Estimates for 162 Countries from 1999 to 2007.' Policy Research Working Paper 5356, The World Bank, Washington, DC.

Silvani, C., and K. Baer. 1997. 'Designing a Tax Administration Reform Strategy: Experiences and Guidelines.' Working Paper wP/97/30, International Monetary Fund, Washington, DC.

Slemrod, J. 1998. 'On Voluntary Compliance, Voluntary Taxes, and Social Capital.' National Tax Journal 51:485-92.

Statistik Austria. 2016. Statistik der Lohnsteuer 2015. Wien: Statistik Austria.

Torgler, B. 2002. 'Speaking to Theorists and Searching for Facts: Tax Morale and Tax Compliance in Experiments.' Journal of Economic Surveys 16 (5): 657-83.

Van Dijke, M., and P. Verboon. 2010. 'Trust in Authorities as a Boundary Condition to Procedural Fairness Effects on Tax Compliance.' Journal of Economic Psychology 31:80-91.

Wenzel, M. 2004a. 'An Analysis of Norm Processes in Tax Compliance.' Journal of Economic Psychology 25 (2): 213-28.

Wenzel, M. 2004b. 'The Social Side of Sanctions: Personal and Social Norms as Moderators of Deterrence.' Law and Human Behavior 28:499-513. 